\title{
40 Zwei Dreigestirne. Von Arbitrage bis Spekulation
}

Die Terminologie der Finanzmärkte scheint weiblich und mitunter auch sächlich zu sein - nur Männlichkeit hat weniger Raum:
die Rendite
das Risiko
die Liquidität
die Arbitrage
die Absicherung
die Spekulation

Je drei dieser Begriffe stehen in engem Zusammenhang.

Rendite - Risiko - Liquidität: Hat ein Investor hohe Liquiditätsanforderungen, will er also stets »flüssig « sein, sodass sein Geld kurzfristig verfügbar ist, muss er im Allgemeinen mit einer geringeren Rendite rechnen. Will er andererseits eine hohe Rendite erwirtschaften, hat er in der Regel auch ein höheres Risiko in Kauf zu nehmen.

Arbitrage - Absicherung - Spekulation: Diese Dreiergruppe charakterisiert die Akteure und Strategien an den Finanzmärkten. Zum einen stehen sich Hedger und Spekulant gegenüber. Ersterer bevorzugt die Sicherheit und ist bereit, einen bestimmten Preis für die Absicherung seines Vermögens oder seiner Geschäfte zu zahlen, indem er das Risiko seinem Vertragspartner, dem Spekulanten, überlässt. Ohne ihn kann er nicht agieren. Letzterer wiederum ist bereit, Risiko zu tragen, natürlich mit der Absicht, Gewinne zu erzielen.

Von Arbitrage, dem Erzielen risikoloser Gewinne ohne den Einsatz eigenen Kapitals durch das Ausnutzen von Preisdifferenzen für ein und dasselbe Produkt auf verschiedenen Märkten, träumt wohl ein jeder. Und weil jeder davon träumt, gibt es Arbitrage (so gut wie) nicht, zumal in unserer modernen Informationsgesellschaft, wo Tausende von Computersystemen über kleinste Preisdifferenzen wachen und Arbitragemöglichkeiten aufspüren. Werden tatsächlich welche gefunden, verschwinden sie im Handumdrehen durch Käufe und Verkäufe und die damit einhergehende Preisanpassung. Daher gehen viele Finanzmarktmodelle aus gutem Grund von der No-Arbitrage-Bedingung aus. 